\title{
Determinants Affecting Quality of Life: Implications for Pharmacist Counseling for Patients with Breast Cancer in Japan
}

\author{
Takashi Kawaguchi, ${ }^{* a}$ Satoru Iwase, ${ }^{b}$ Masayoshi Koinuma, ${ }^{c}$ Yuki Onodera,${ }^{a}$ Hironori Takeuchi, ${ }^{a}$ \\ Megumi Umeda, ${ }^{d}$ Tadaharu Matsunaga, ${ }^{d}$ Sakae Unezaki,${ }^{a}$ and Yoshinori Nagumo ${ }^{d}$ \\ ${ }^{a}$ Department of Practical Pharmacy, School of Pharmacy, Tokyo University of Pharmacy and Life Sciences; 1432-1 \\ Horinouchi, Hachioji, Tokyo 192-0392, Japan: ${ }^{b}$ Department of Palliative Medicine, The University of Tokyo Hospi- \\ tal; 7-3-1 Hongo, Bunkyo-ku, Tokyo 113-8655, Japan: ' Nihon University School of Pharmacy; 7-7-1 Narashinodai, \\ Funabashi, Chiba 274-8555, Japan: and ${ }^{d}$ Nagumo Clinic; 1-11-2 Ohsaki, Shinagawa-ku, Tokyo 141-0032, Japan.
}

Received August 3, 2011; accepted October 29, 2011; published online October 31, 2011

\begin{abstract}
Although pharmacist counseling assumes an important role in the clinical setting, oncology pharmacy practitioners worldwide currently lack adequate guidance. This study aimed to identify the determinants and causal relationships that affect quality of life (QOL) in breast cancer patients before adjuvant systemic therapy for improving pharmacist counseling and guidance. This study analyzed 93 postoperative patients with breast cancer before pharmacist counseling for adjuvant systemic therapy. Patients were asked to complete questionnaires to assess QOL (the European Organisation for Research and Treatment of Cancer Quality of Life Questionnaire C30 [EORTC QLQ-C30] and its breast cancer module [EORTC QLQ-BR23]) before pharmacist counseling. We analyzed factors affecting QOL by stepwise multiple linear regression analysis and evaluated causal association using path analysis. In the multiple linear regression model using variables selected by stepwise analysis, the factors affecting global health status (GHS)/QOL included fatigue, emotional functioning, systemic therapy side effects, future perspectives, and appetite loss. In the path analysis model, GHS/QOL were strongly influenced by fatigue directly; and emotional functioning, directly and indirectly via other factors. Our results indicated that fatigue and emotional functioning are strong factors affecting QOL. These factors may be able to predict poor QOL before initiating adjuvant systemic therapy. Thus, our findings suggest that these factors may be potentially useful for pharmacist counseling at the beginning of adjuvant systemic therapy.
\end{abstract}

Key words pharmacist counseling; breast cancer; quality of life; adjuvant therapy; patient-centered

The incidence of breast cancer is increasing worldwide, and breast cancer has now become the most common cancer in Japanese women. In 2005, approximately 50000 Japanese women were newly diagnosed with breast cancer. ${ }^{1)}$ This is an increase of about $60 \%$ from a decade ago. ${ }^{2}$ In recent years, the measurement of quality of life (QOL) has been recognized to be important and is required in most clinical trials. Healthrelated quality of life (HRQOL) is described as physical, psychological, emotional, social, and well-being. ${ }^{3)}$ The diagnosis of breast cancer affects patients' HRQOL, and is considered a severe stressor. ${ }^{4,5}$ Many previous studies have shown that psychological distress influences breast cancer mortality, compliance, and HRQOL. ${ }^{6-10}$ In patients newly diagnosed with breast cancer, the prevalence of depression ranges from 1.5 to $46 \%{ }^{11-13)}$ Furthermore, the effects of adjuvant systemic therapy received by breast cancer patients have a negative impact on QOL. ${ }^{14-16)}$ Therefore, it is important to provide information to patients about the influence of these therapies on QOL before they determine their therapeutic preferences. ${ }^{17,18)}$

In oncology-related pharmacy, pharmacists' competencies are moving from traditional drug-oriented services toward patient-oriented services. ${ }^{19,20)}$ In 2005, The Japanese Society of Hospital Pharmacists established the certifications for boardcertified oncology pharmacy specialists and board-certified pharmacists in oncology pharmacy. As in other countries, the clinical role of pharmacists in Japan is expanding. ${ }^{21}$ The concordance and communication between patients and pharmacists may improve patients' understanding of pharmacotherapy, ${ }^{22,23)}$ and pharmacist intervention has been shown to result in improved patient care. ${ }^{24)}$ However, there is little scientific information to guide pharmacist counseling in oncology. Additionally, there is no sufficient evidence based on which proactive specific questions can be asked when talking to cancer patients.

Recently, patient-reported outcome measurements of subjective measurement of symptoms has attracted increasing attention in clinical trials ${ }^{25,26)}$ and health care settings. ${ }^{27)}$ Basch et al. reported that patient reported symptoms were more in accordance with measures of daily health status than clinician reported symptoms. ${ }^{28)}$ In the present study, we hypothesized that analysis of patient-reported outcomes would render pharmacist counseling more proactive and patient-centered. The aim of this study was to investigate the rationale for pharmacist counseling by analyzing the factors affecting QOL among patients with breast cancer prior to pharmacist counseling.

\section{MATERIALS AND METHODS}

Study Design and Data Collection We studied postoperative breast cancer patients before pharmacist counseling for adjuvant systemic therapy at Nagumo Clinic in Tokyo from December 2008 to May 2011. This study had a cross-sectional design. The eligibility criteria for patients' enrollment were as follows: after receiving trans-areolar total glandectomy or breast-sparing surgery, histologically confirmed invasive ductal carcinoma of the breast, no cognitive impairment, and initial ambulatory care after surgery. Patients who were not Japanese or those with severe psychiatric disease were excluded. To assess and analyze the patients' physical and emotional conditions, our clinic obtained signed consent from the 
patients and asked them to complete QOL-assessment questionnaires at the clinic before to decide on specific adjuvant systemic therapy. All patients who met the eligibility criteria were selected from among these outpatients. Patient demographics were collected from medical records. This study was approved by the local institutional review board of Nagumo Clinic, which allowed us to analyze the obtained data without necessarily requiring patient consent because the study involved no intervention, and the data were anonymized.

Measures. QOL From the various instruments available for Japanese patients, we choose the European Organisation for Research and Treatment of Cancer (EORTC) Quality of Life Questionnaire (QLQ)-C30 version 3.0 (30 items) ${ }^{29)}$ and its breast cancer module, EORTC QLQ-BR23 (23 items), ${ }^{30)}$ in order to analyze the relationship between QOL and other components. The QLQ-C30 is composed of 5 functional scales (physical, role, emotional, cognitive, and social functioning), a global health status/QOL scale, and 9 symptoms scales (fatigue, nausea and vomiting, pain, dyspnea, insomnia, appetite loss, constipation, diarrhea, and financial difficulties). The BR23 evaluates 4 functional aspects (body image, sexual functioning, sexual enjoyment, and future perspectives) and 4 sets of common symptoms (systemic therapy side effects, breast symptoms, arm symptoms, and upset by hair loss). The validity and reliability of the Japanese version of EORTC QLQ-C30 and BR-23 have been previously verified. ${ }^{31,32)}$ Both the questionnaires were self administered at the outpatient clinic. The scoring of the raw data of the EORTC QLQ-C30 and BR23 into a linear scale ranging from 0 to 100 was performed according to the scoring manual. Higher function scores represented good QOL, while higher symptom scores indicated poor QOL.

Statistical Methods Exploratory analyses, including Spearman rank correlations and stepwise multiple linear regression analysis, were conducted as indicated using JMP, version 8.0.2 ${ }^{\circledR}$ (SAS Institute Inc., Cary, NC, U.S.A.). Descriptive statistics including mean and standard deviation were used to summarize patients' demographics and QOL score. To determine the relationship between the variables of EORTC QLQ-C30 and BR23, Spearman rank correlations were calculated. To determine the variables affecting QOL, stepwise multiple linear regression analysis was conducted to test the statistical association between global health status (GHS)/QOL and other EORTC QLQ-C30 and BR23 parameters (9 functions and 13 symptoms). A sample size of 93 was estimated on the basis of our previous research in which the GHS/QOL score was assumed to predict 5 variables with "medium" effect size, a power of $80 \%$, and alpha level of $0.05 .{ }^{33,34)}$ Variables that were not statistically significant at the 0.05 level for Spearman rank correlations were excluded from the stepwise analyses. Forward stepwise selections were administered on the variables that were correlated with GHS/QOL score. The entry criterion was a $p$ value of $<0.05$. In selected variables identified by the stepwise analysis, multiple linear regression analysis was conducted. Moreover, we examined the causal association by means of path analysis carried out using Amos $18^{\circledR}$ (SPSS Inc., Chicago, IL, U.S.A.). Path analysis is the statistical technique used to examine causal relations between variables of specialized model. We used 4 indices to evaluate the optimum model: the goodness-of-fit index (GFI), the adjusted goodness-of-fit index (AGFI), the root mean square error of approximation (RMSEA), and the Akaike Information Criterion (AIC).

\section{RESULTS}

Patient Characteristics In all, 95 patients were recruited in the present study. Two patients who are not Japanese were excluded. Finally, 93 patients were analyzed. All patients were female, and the mean (S.D.) age was 47.3 (9.0) years. Sixty-four patients $(68.9 \%)$ were diagnosed with Stage I breast cancer. Sixty-seven patients (72\%) were premenopausal, and 62 patients $(67 \%)$ were married. Lymph node involvement was negative in $81 \%$ of patients, while $16 \%$ had $1-3$ positive nodes and $3 \%$ had 4 or more positive nodes. Further, $83 \%$ of patients had undergone reconstructive mammoplasty. After surgery, approximately $95 \%$ of patients received initial ambulatory care within 2 months of surgery.

Assessment of QOL Table 1 shows the results of the EORTC QLQ-C30 and BR23 scoring. The mean score for GHS/QOL was 68.1, and ranged from 16.7 to 100 . The distress caused by hair loss could not be evaluated because all patients were evaluated prior to pharmacotherapy; however, all other symptoms were observed and assessed. Even before starting pharmacotherapy, systemic therapy side effects were observed and scored; the mean score was 11.2, ranging from 0 to 52.4. Data were missing for sexual functioning and sexual enjoyment in 8 and 76 patients, respectively.

Table 1. Results of EORTC QLQ-C30 and BR23 Scores

\begin{tabular}{|c|c|c|}
\hline \multirow{2}{*}{ Variable } & \multicolumn{2}{|c|}{ Score } \\
\hline & Mean & S.D. \\
\hline \multicolumn{3}{|l|}{ EORTC QLQ-C30 } \\
\hline Global health status/QOL & 68.1 & 21.6 \\
\hline \multicolumn{3}{|l|}{ Function } \\
\hline Physical functioning & 87.0 & 12.8 \\
\hline Role functioning & 82.3 & 19.6 \\
\hline Emotional functioning & 77.3 & 15.4 \\
\hline Cognitive functioning & 86.8 & 14.7 \\
\hline Social functioning & 84.6 & 20.4 \\
\hline \multicolumn{3}{|l|}{ Symptom } \\
\hline Fatigue & 28.9 & 22.7 \\
\hline Nausea/Vomiting & 2.7 & 8.3 \\
\hline Pain & 26.7 & 22.7 \\
\hline Dyspnea & 10.7 & 21.0 \\
\hline Insomnia & 19.6 & 26.2 \\
\hline Appetite loss & 7.2 & 19.7 \\
\hline Constipation & 21.5 & 27.2 \\
\hline Diarrhea & 5.7 & 12.6 \\
\hline Financial difficulties & 19.0 & 23.4 \\
\hline \multicolumn{3}{|l|}{ EORTC BR23 } \\
\hline Body image & 74.1 & 22.3 \\
\hline Sexual functioning $(n=85)$ & 90.3 & 13.7 \\
\hline Sexual enjoyment $(n=17)$ & 71.6 & 20.0 \\
\hline Future perspectives & 46.5 & 28.9 \\
\hline Systemic therapy side effects & 11.2 & 10.9 \\
\hline Breast symptoms & 27.6 & 19.8 \\
\hline Arm symptoms & 25.8 & 16.9 \\
\hline
\end{tabular}

EORTC $=$ the European organisation for research and treatment of cancer, $\mathrm{QLQ}=$ quality of life questionnaire, $\mathrm{QOL}=$ quality of life, S.D.=standard deviation. 


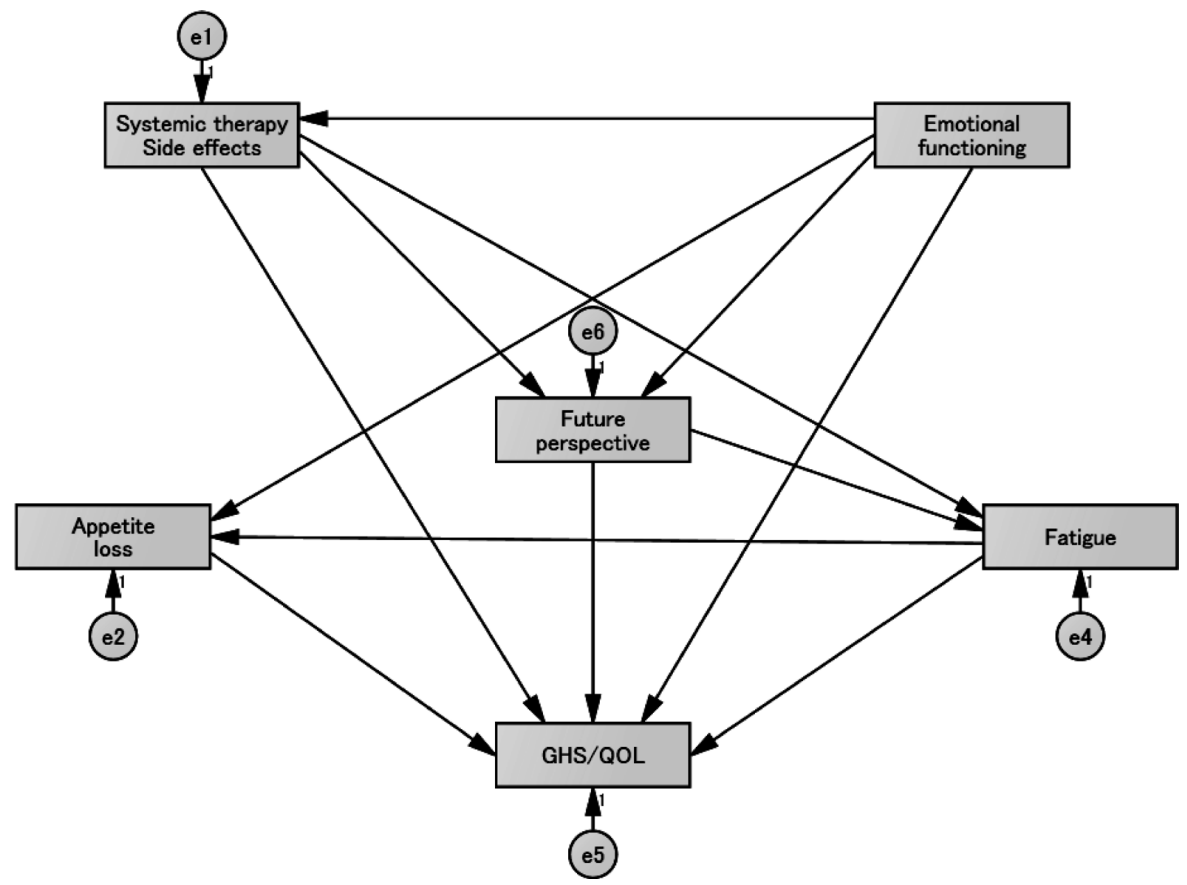

Fig. 1. Path Analysis Using Variables Selected by Stepwise Analysis *e; error variable.

Factors Affecting QOL Variables that were not statistically significant at the 0.05 level were as follows: nausea/vomiting (Spearman correlation coefficient, -0.15$)$, constipation $(-0.13)$, diarrhea $(0.11)$, sexual functioning $(0.12)$, and sexual enjoyment (0.09). After excluding these variables, stepwise analyses were conducted. Five variables - emotional functioning, fatigue, appetite loss, future perspectives, and systemic therapy side effects - were selected. Finally, multiple linear regression analysis was conducted. The $R^{2}$ and adjusted $R^{2}$ values were 0.63 and 0.61 , respectively. Of the selected variables, fatigue (standardized coefficient $-0.54, p \leq 0.0001$ ) had a strong affect on QOL. Standardized coefficients of emotional functioning, appetite loss, future perspectives, and systemic therapy side effects were $0.23(p=0.0092),-0.15(p=0.0471)$, $0.24(p=0.0092)$, and $0.19(p=0.0347)$, respectively. These multiple linear regression analyses revealed that the influence of fatigue on QOL was twice as strong as that of the other factors.

Causal Association of Factors Affecting QOL Based on fit indices of path analysis, the final model was selected (Fig. 1). This model provided a good fit to the data (GFI $=0.997$, AGFI $=0.976$, and RMSEA=0.000). Standardized direct, indirect, and total effects are shown in Table 2. As with the result of the multiple linear regression analyses, the strongest standardized direct effect on GHS/QOL was -0.543 of fatigue. This effect of fatigue was approximately 2 times higher than the standardized effect of emotional functioning, which was the second strongest standardized direct effect. The standardized indirect effects of systemic therapy side effects and emotional functioning on GHS/QOL were -0.380 and 0.310 , respectively, in descending order. Finally, on the basis of the standardized total effect, which was the sum of the standardized direct and indirect effects, fatigue and emotional functioning were the strongest factors $(0.587,0.544$, respectively) in affecting GHS/QOL. In this model, emotional func- tioning, systemic therapy side effects, and future perspectives were responsible for fatigue. Among these, the standardized total effect of systemic therapy side effects was the highest, and the influence of systemic therapy side effects was more than twice that of future perspectives. Emotional functioning influenced fatigue only indirectly but strongly. Table 2 shows that emotional functioning had a uniformly strong influence on other variables. The indirect effect of systemic therapy side effects $(-0.380)$ negatively influenced GHS/QOL, whereas the direct effect $(0.189)$ had no such influence.

\section{DISCUSSION}

To explore the rationale for pharmacist counseling, we evaluated the factors affecting QOL in the initial ambulatory care setting among patients with postoperative breast cancer. Stepwise multiple regression analysis showed 5 factors affecting QOL. Moreover, path analysis revealed a causal association between these factors and QOL; therefore, we considered emotional functioning to have a strong influence on GHS/ QOL.

In this study, all the patients had already undergone surgery, but had not yet been provided adjuvant systemic therapy; however, our analysis showed that systemic therapy side effects affected the QOL. In the EORTC-BR23, systemic therapy side effects consisted of 7 symptoms as follows: dry mouth, taste disorder, pain, hair loss, feeling of being unwell, hot flushes, and headache. Although our analysis was unable to clearly reveal the cause of systemic therapy side effects, the surgery itself, menopausal state, depression, and anxiety were considered to be possible reasons contributing to the systemic therapy side effects score.

With stepwise selection, multiple linear regression analysis and path analysis revealed that fatigue was the strongest factor among the factors affecting QOL. Cancer-related fatigue 
Table 2. Standardized Direct, Indirect and Total Effects of Path Analysis $(\mathrm{GFI}=0.997$, AGFI $=0.976$, and RMSEA=0.000)

\begin{tabular}{|c|c|c|c|c|c|c|c|c|c|c|c|c|c|c|c|}
\hline & \multicolumn{3}{|c|}{$\mathrm{EF}$} & \multicolumn{3}{|c|}{ BRST } & \multicolumn{3}{|c|}{ BRFU } & \multicolumn{3}{|c|}{ FA } & \multicolumn{3}{|c|}{ AP } \\
\hline & Direct & Indirect & Total & Direct & Indirect & Total & Direct & Indirect & Total & Direct & Indirect & Total & Direct & Indirect & Total \\
\hline & (A) & (B) & $(\mathrm{A}+\mathrm{B})$ & (A) & (B) & $(A+B)$ & (A) & (B) & $(A+B)$ & (A) & (B) & $(\mathrm{A}+\mathrm{B})$ & (A) & (B) & $(A+B)$ \\
\hline BRST & -0.483 & - & -0.483 & - & - & - & - & - & - & - & - & - & - & - & - \\
\hline BRFU & 0.508 & 0.117 & 0.625 & -0.242 & - & -0.242 & - & - & - & - & - & - & - & - & - \\
\hline FA & - & -0.377 & -0.377 & 0.495 & 0.054 & 0.549 & -0.221 & - & -0.221 & - & - & - & - & - & - \\
\hline AP & -0.209 & -0.115 & -0.324 & - & 0.167 & 0.167 & - & -0.067 & -0.067 & 0.304 & - & 0.304 & - & - & - \\
\hline $\begin{array}{l}\text { GHS/ } \\
\text { QOL }\end{array}$ & 0.235 & 0.310 & 0.544 & 0.189 & -0.380 & -0.191 & 0.237 & 0.130 & 0.367 & -0.543 & -0.045 & -0.587 & -0.147 & - & -0.147 \\
\hline
\end{tabular}

$\mathrm{GHS}=$ global health status, $\mathrm{QOL}=$ quality of life, $\mathrm{EF}=$ emotional functioning, $\mathrm{BRST}=$ systemic therapy side effects, $\mathrm{BRFU}=$ future perspectives, $\mathrm{FA}=$ fatigue, $\mathrm{AP}=$ appetite loss.

is known as a common problem among cancer patients and is attributed not only to physiological factors but also to psychosocial factors. ${ }^{35)}$ In our model of path analysis, systemic therapy side effects and future perspectives directly affected fatigue. In addition, emotional functioning indirectly influenced fatigue via future perspectives. Because our study did not survey QOL after initiating adjuvant systemic treatment, we could not provide an analysis of the causes of deteriorating QOL. However, these results revealed that there are patients with poor QOL even before adjuvant systemic therapy that was caused by not only fatigue directly but also emotional functioning indirectly. These results may enable pharmacists to ask proactive questions based on the knowledge of these causal relationships, and our results may thus be potentially useful for pharmacist counseling.

It is well known that adjuvant systemic therapy, including chemotherapy and endocrine therapy, affect QOL adversely. ${ }^{15,36,37)}$ The adverse effects on QOL are due to physical symptoms caused by adjuvant systemic therapy as well as emotional effects. Pharmacist counseling cannot change the physical side effects of adjuvant systemic therapy but may be able to prevent deterioration of QOL by emotionally preparing the patient to tolerate the side effects. Thus, before initiating adjuvant systemic therapy, pharmacist counseling regarding QOL becomes important. The effects of pharmacist counseling and intervention have been previously evaluated. Yuan et al. reported that pharmacist counseling has a favorable effect on hospitalization. ${ }^{38)}$ Stevens et al. evaluated the effect of pharmacist intervention on the eradication of Helicobacter pylori in a randomized controlled trial ${ }^{39)}$ and found that pharmacist intervention improved patient satisfaction but did not affect adherence. Nevertheless, there have been few reports regarding the efficacy of pharmacist counseling and intervention in oncology, especially in Japan. Although the design of our study could not assess the effect of pharmacist counseling on QOL, further studies are warranted for investigating the relationships between pharmacist counseling and determinants of QOL.

Our study was limited by a somewhat poor response rate on questions regarding sexual functioning and sexual enjoyment, with almost no patients replying to the question on sexual enjoyment. Accordingly, we were not able to examine the influence of sexual problems on QOL. It is widely recognized that sexual problems are significant issues in women with breast cancer. ${ }^{40-42)}$ As in western countries, patients with breast cancer in Japan have been found to have various sexual problems. ${ }^{43-46)}$ Moreover, in Japan, the patient-physician relationship is subject to cultural constraints. Japanese patients tend to hesitate to express themselves, but at the same time, they consider that physicians do not listen to them. ${ }^{47)}$ Such a cultural inhibition might be a factor responsible for the poor response rate with regard to the question on sexual enjoyment.

In the results of our analyses, we identified 5 factors as determinants affecting baseline QOL before pharmacist counseling. Recent years, baseline QOL assessment is becoming more important. In the meta-analysis of EORTC clinical trials, baseline QOL was revealed as prognostic indicator of survival. $^{48)}$ Furthermore, appropriate information provision positively correlated with QOL. ${ }^{49}$ ) The aim of information provision is to prepare patients for their treatment, to increase adherence to therapy, and to increase their abilities to cope with the illness, ${ }^{50}$ ) hence baseline QOL is one of the significant information for pharmacist counseling. Because 5 factors we identified may predict poor QOL and survival, pharmacist should note patients with these factors on pharmacist counseling before initiating systemic therapy to provide appropriate information provision, to select treatment options and to support decision making.

\section{CONCLUSIONS}

By analyzing patient-reported outcome questionnaires, we identified 5 factors-fatigue, emotional functioning, systemic therapy side effects, future perspectives, and appetite lossas determinants affecting QOL. Our findings suggest that considering these factors maybe potentially aid pharmacist counseling at the start of systemic therapy. Further studies on pharmacist counseling that considers these factors are needed to improve QOL outcomes.

Acknowledgments Editorial and publication support was provided by Editage. This research received no specific grant from any funding agency in the public, commercial, or notfor-profit sectors.

Conflict of Interest Statement The authors declare that there are no competing interests.

\section{REFERENCES}

1) Matsuda T, Marugame T, Kamo K, Katanoda K, Ajiki W, Sobue T. Japan Cancer Surveillance Research Group. Cancer incidence and 
incidence rates in Japan in 2005: based on data from 12 populationbased cancer registries in the Monitoring of Cancer Incidence in Japan (MCIJ) project. Jpn. J. Clin. Oncol., 41, 139-147 (2011).

2) The Research Group for Population-based Cancer Registration in Japan. Cancer incidence and incidence rates in Japan in 1995: estimates based on data from nine population-based cancer registries. Jpn. J. Clin. Oncol., 30, 318-321 (2000).

3) Fallowfield L. Quality of life: a new perspective for cancer patients. Nat. Rev. Cancer, 2, 873-879 (2002).

4) Iwamitsu Y, Shimoda K, Abe H, Tani T, Okawa M, Buck R. Anxiety, emotional suppression, and psychological distress before and after breast cancer diagnosis. Psychosomatics, 46, 19-24 (2005).

5) Arndt V, Stegmaier C, Ziegler H, Brenner H. A population-based study of the impact of specific symptoms on quality of life in women with breast cancer 1 year after diagnosis. Cancer, 107, 2496-2503 (2006).

6) Hjerl K, Andersen EW, Keiding N, Mouridsen HT, Mortensen PB, Jørgensen T. Depression as a prognostic factor for breast cancer mortality. Psychosomatics, 44, 24-30 (2003).

7) Ayres A, Hoon PW, Franzoni JB, Matheny KB, Cotanch PH, Takayanagi $S$. Influence of mood and adjustment to cancer on compliance with chemotherapy among breast cancer patients. J. Psychosom. Res., 38, 393-402 (1994).

8) Burgess C, Cornelius V, Love S, Graham J, Richards M, Ramirez A. Depression and anxiety in women with early breast cancer: five year observational cohort study. BMJ, 330, 702 (2005).

9) Golden-Kreutz DM, Andersen BL. Depressive symptoms after breast cancer surgery: relationships with global, cancer-related, and life event stress. Psychooncology, 13, 211-220 (2004).

10) Ando N, Iwamitsu Y, Kuranami M, Okazaki S, Wada M, Yamamoto K, Todoroki K, Watanabe M, Miyaoka H. Psychological characteristics and subjective symptoms as determinants of psychological distress in patients prior to breast cancer diagnosis. Support. Care Cancer, 17, 1361-1370 (2009).

11) Hegel MT, Moore CP, Collins ED, Kearing S, Gillock KL, Riggs RL, Clay KF, Ahles TA. Distress, psychiatric syndromes, and impairment of function in women with newly diagnosed breast cancer. Cancer, 107, 2924-2931 (2006).

12) Wong-Kim EC, Bloom JR. Depression experienced by young women newly diagnosed with breast cancer. Psychooncology, 14, $564-573$ (2005).

13) Massie MJ. Prevalence of depression in patients with cancer. $J$. Natl. Cancer Inst. Monogr., 32, 57-71 (2004).

14) Fan HG, Houédé-Tchen N, Yi QL, Chemerynsky I, Downie FP, Sabate K, Tannock IF. Fatigue, menopausal symptoms, and cognitive function in women after adjuvant chemotherapy for breast cancer: 1- and 2-year follow-up of a prospective controlled study. J. Clin. Oncol., 23, 8025-8032 (2005).

15) Fallowfield L, Cella D, Cuzick J, Francis S, Locker G, Howell A. Quality of life of postmenopausal women in the Arimidex, Tamoxifen, Alone or in Combination (ATAC) Adjuvant Breast Cancer Trial. J. Clin. Oncol., 22, 4261-4271 (2004).

16) Fallowfield LJ, Bliss JM, Porter LS, Price MH, Snowdon CF, Jones SE, Coombes RC, Hall E. Quality of life in the intergroup exemestane study: a randomized trial of exemestane versus continued tamoxifen after 2 to 3 years of tamoxifen in postmenopausal women with primary breast cancer. J. Clin. Oncol., 24, 910-917 (2006).

17) Hack TF, Degner LF, Dyck DG. Relationship between preferences for decisional control and illness information among women with breast cancer: a quantitative and qualitative analysis. Soc. Sci. Med., 39, 279-289 (1994).

18) Degner LF, Kristjanson LJ, Bowman D, Sloan JA, Carriere KC O’Neil J, Bilodeau B, Watson P, Mueller B. Information needs and decisional preferences in women with breast cancer. JAMA, 277, 1485-1492 (1997).

19) Jaehde U, Liekweg A, Simons S, Westfeld M. Minimising treatment-associated risks in systemic cancer therapy. Pharm. World
Sci., 30, 161-168 (2008)

20) Liekweg A, Westfeld M, Jaehde U. From oncology pharmacy to pharmaceutical care: new contributions to multidisciplinary cancer care. Support. Care Cancer, 12, 73-79 (2004).

21) Ikesue H, Oishi R. Oncology pharmacy specialists in oncology. Gan To Kagaku Ryoho, 35, 578-582 (2008).

22) Onda M, Sakurai H, Hayase Y, Sakamaki H, Arakawa Y, Yasukawa F. Effects of patient-pharmacist communication in the treatment of asthma. Yakugaku Zasshi, 129, 427-433 (2009).

23) Chewning B, Wiederholt JB. Concordance in cancer medication management. Patient Educ. Couns., 50, 75 -78 (2003).

24) Kaboli PJ, Hoth AB, McClimon BJ, Schnipper JL. Clinical pharmacists and inpatient medical care: a systematic review. Arch. Intern. Med., 166, 955-964 (2006).

25) Bruner DW. Should patient-reported outcomes be mandatory for toxicity reporting in cancer clinical trials? J. Clin. Oncol., 25, $5345-5347$ (2007).

26) Acquadro C, Berzon R, Dubois D, Leidy NK, Marquis P, Revicki D, Rothman M; PRO Harmonization Group. Incorporating the patient's perspective into drug development and communication: an ad hoc task force report of the Patient-Reported Outcomes (PRO) Harmonization Group meeting at the Food and Drug Administration, February 16, 2001. Value Health, 6, 522-531 (2003).

27) Dawson J, Doll H, Fitzpatrick R, Jenkinson C, Carr AJ. The routine use of patient reported outcome measures in healthcare settings. $B M J, 340$ (jan18 1), c186 (2010).

28) Basch E, Jia X, Heller G, Barz A, Sit L, Fruscione M, Appawu M, Iasonos A, Atkinson T, Goldfarb S, Culkin A, Kris MG, Schrag D. Adverse symptom event reporting by patients vs clinicians: relationships with clinical outcomes. J. Natl. Cancer Inst., 101, 1624-1632 (2009).

29) Aaronson NK, Ahmedzai S, Bergman B, Bullinger M, Cull A, Duez NJ, Filiberti A, Flechtner H, Fleishman SB, de Haes JC. The European Organization for Research and Treatment of Cancer QLQ-C30: a quality-of-life instrument for use in international clinical trials in oncology. J. Natl. Cancer Inst., 85, 365-376 (1993).

30) Sprangers MA, Groenvold M, Arraras JI, Franklin J, te Velde A, Muller M, Franzini L, Williams A, de Haes HC, Hopwood P, Cull A, Aaronson NK. The European Organization for Research and Treatment of Cancer breast cancer-specific quality-of-life questionnaire module: first results from a three-country field study. J. Clin. Oncol., 14, 2756-2768 (1996)

31) Kobayashi K, Takeda F, Teramukai S, Gotoh I, Sakai H, Yoneda S, Noguchi Y, Ogasawara H, Yoshida K. A cross-validation of the European Organization for Research and Treatment of Cancer QLQ-C30 (EORTC QLQ-C30) for Japanese with lung cancer. Eur. J. Cancer, 34, 810-815 (1998).

32) Okamoto T, Shimozuma K, Katsumata N, Koike M, Hisashige A, Tanaka K, Ohsumi S, Saito M, Shikama N, Mitsumori M, Yamauchi C, Watanabe T. Task Force of the Japanese Breast Cancer Society for 'The Development of Guidelines for Quality of Life Assessment Studies of Breast Cancer Patients.' Measuring quality of life in patients with breast cancer: a systematic review of reliable and valid instruments available in Japan. Breast Cancer, 10, 204-213 (2003)

33) Faul F, Erdfelder E, Lang AG, Buchner AG. G* Power 3: a flexible statistical power analysis program for the social, behavioral, and biomedical sciences. Behav. Res. Methods, 39, 175-191 (2007).

34) Faul F, Erdfelder E, Buchner A, Lang AG. Statistical power analyses using $\mathrm{G}^{*}$ Power 3.1: tests for correlation and regression analyses. Behav. Res. Methods, 41, 1149-1160 (2009).

35) Ahlberg K, Ekman T, Gaston-Johansson F, Mock V. Assessment and management of cancer-related fatigue in adults. Lancet, $\mathbf{3 6 2}$, $640-650$ (2003).

36) Baum M, Budzar AU, Cuzick J, Forbes J, Houghton JH, Klijn JG, Sahmoud T; ATAC Trialists' Group. Anastrozole alone or in combination with tamoxifen versus tamoxifen alone for adjuvant 
treatment of postmenopausal women with early breast cancer: first results of the ATAC randomised trial. Lancet, 359, 2131-2139 (2002).

37) Ganz PA, Coscarelli A, Fred C, Kahn B, Polinsky ML, Petersen L. Breast cancer survivors: psychosocial concerns and quality of life. Breast Cancer Res. Treat., 38, 183-199 (1996).

38) Yuan Y, Hay JW, McCombs JS. Effects of ambulatory-care pharmacist consultation on mortality and hospitalization. Am. J. Manag. Care, 9, 45-56 (2003).

39) Stevens VJ, Shneidman RJ, Johnson RE, Boles M, Steele PE, Lee NL. Helicobacter pylori eradication in dyspeptic primary care patients: a randomized controlled trial of a pharmacy intervention. West. J. Med., 176, 92-96 (2002).

40) Ganz PA, Kwan L, Stanton AL, Krupnick JL, Rowland JH, Meyerowitz BE, Bower JE, Belin TR. Quality of life at the end of primary treatment of breast cancer: first results from the moving beyond cancer randomized trial. J. Natl. Cancer Inst., 96, 376-387 (2004).

41) Ganz PA, Desmond KA, Leedham B, Rowland JH, Meyerowitz BE, Belin TR. Quality of life in long-term, disease-free survivors of breast cancer: a follow-up study. J. Natl. Cancer Inst., 94, 39-49 (2002).

42) Ganz PA, Desmond KA, Belin TR, Meyerowitz BE, Rowland JH. Predictors of sexual health in women after a breast cancer diagnosis. J. Clin. Oncol., 17, 2371-2380 (1999).

43) Takahashi M, Ohno S, Inoue H, Kataoka A, Yamaguchi H, Uchida Y, Oshima A, Abiru K, Ono K, Noguchi R, Kai I. Impact of breast cancer diagnosis and treatment on women's sexuality: a survey of Japanese patients. Psychooncology, 17, 901—907 (2008).
44) Laumann EO, Nicolosi A, Glasser DB, Paik A, Gingell C, Moreira E, Wang T. GSSAB Investigators' Group. Sexual problems among women and men aged $40-80 \mathrm{y}$ : prevalence and correlates identified in the Global Study of Sexual Attitudes and Behaviors. Int. J. Impot. Res., 17, 39-57 (2005).

45) Takahashi M, Kai I. Sexuality after breast cancer treatment: changes and coping strategies among Japanese survivors. Soc. Sci. Med., 61, 1278-1290 (2005).

46) Moreira ED Jr, Brock G, Glasser DB, Nicolosi A, Laumann EO, Paik A, Wang T, Gingell C. GSSAB Investigators' Group. Helpseeking behaviour for sexual problems: the global study of sexual attitudes and behaviors. Int. J. Clin. Pract., 59, 6-16 (2005).

47) Okamoto $\mathrm{S}$. Transformations in doctor-patient communication in Japan: the role of cultural factors. Patient Educ. Couns., 65, 153155 (2007)

48) Quinten C, Coens C, Mauer M, Comte S, Sprangers MA, Cleeland C, Osoba D, Bjordal K, Bottomley A. EORTC Clinical Groups. Baseline quality of life as a prognostic indicator of survival: a meta-analysis of individual patient data from EORTC clinical trials. Lancet Oncol., 10, 865-871 (2009).

49) Husson O, Mols F, van de Poll-Franse LV. The relation between information provision and health-related quality of life, anxiety and depression among cancer survivors: a systematic review. Ann. Oncol., 22, 761-772 (2011).

50) van der Meulen N, Jansen J, van Dulmen S, Bensing J, van Weert $\mathrm{J}$. Interventions to improve recall of medical information in cancer patients: a systematic review of the literature. Psychooncology, 17, $857-868$ (2008). 